\title{
Early-stage oxidation behavior at high temperatures of SiSiC cellular architectures in a porous burner
}

\author{
Ehsan Rezaei $^{\mathrm{a}, \mathrm{b}}$, Sophia Haussener ${ }^{\mathrm{b}}$, Sandro Gianella ${ }^{\mathrm{c}}$, Alberto Ortona ${ }^{\mathrm{a}, *}$ \\ a ICIMSI-SUPSI, Manno, 6928 Switzerland \\ ${ }^{\mathrm{b}}$ Institute of Mechanical Engineering, EPFL, Lausanne, 1015 Switzerland

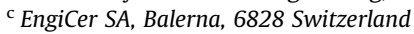

\section{A R T I C L E I N F O}

\section{Article history:}

Received 28 May 2016

Received in revised form

22 July 2016

Accepted 22 July 2016

\section{Keywords:}

Ceramic lattices

Reactive silicon infiltration

High temperature oxidation

Combustion environment

\begin{abstract}
A B S T R A C T
Early stage oxidation behavior of SiSiC cellular lattices with different cell types was studied at $1400{ }^{\circ} \mathrm{C}$ in two different environments: a porous burner and an electric furnace with stagnant air. Oxidation and silicon alloy bead formation were observed and identified as the most important factors affecting the integrity of the structures. Low melting temperature silicon-based alloys formed from the material due to presence of impurities. Having lower melting point than the thermal tests temperature, the beads exuded from the microstructure leaving pores in the substrate material and leading to enhanced oxidation on the surface. Moreover, it was observed that different lattice architectures lead to different oxidation behavior on the struts as a result of the changing gas flow paths inside each ceramic architecture.
\end{abstract}

(c) 2016 Elsevier Ltd and Techna Group S.r.l. All rights reserved.

\section{Introduction}

Open-celled cellular ceramics are attractive materials for high temperature applications such as solar receivers, heat exchangers, porous burners and reformers [1-3]. Among the potential ceramic materials which can be shaped in a cellular architecture, silicon infiltrated $\mathrm{SiC}(\mathrm{SiSiC})$ is particularly interesting due to its outstanding mechanical and thermal properties at high temperatures. SiSiC porous periodic architectures have recently been produced using replica technique of lattice structures obtained from polymeric templates made by $3 \mathrm{D}$ printing followed by reactive infiltration of silicon [4].

$\mathrm{SiSiC}$ cellular ceramics are currently industrially employed as burner components [5] at high temperatures $\left(\sim 1400^{\circ} \mathrm{C}\right)$ in oxidative conditions. Indeed, porous $\mathrm{SiSiC}$ has proven to withstand long operating conditions in a combustion environment [6,7]. It has been noted that foams' behavior is strongly affected by the way they interact with the environment during the very initial phases of operation. This is the result of high thermal shocks imposed to the structures during the ignition and the cooling phases of the operation, leading to high thermo-mechanical loads on the struts and the nodes [1]. Moreover, long operating times at high temperatures requires good corrosion resistance. The oxidation

\footnotetext{
* Corresponding author.

E-mail address: alberto.ortona@supsi.ch (A. Ortona).
}

behavior of silicon and SiC is very complex due to different parameters and species participating in the reactions. Two main oxidation modes have been observed in presence of oxygen, depending on its partial pressure, temperature and mass flow velocity. At very high temperatures and low oxygen partial pressure, or very high velocities (over $100 \mathrm{~m} / \mathrm{s}$ ), the so-called active oxidation is dominant and the material is gradually consumed by the following reactions $[8-10]$ :

$2 \mathrm{Si}+\mathrm{O}_{2} \rightarrow 2 \mathrm{SiO}(\mathrm{g})$

$\mathrm{SiC}+\mathrm{O}_{2} \rightarrow \mathrm{SiO}(\mathrm{g})+\mathrm{CO}(\mathrm{g})$

In this case a linear mass loss is observed due to volatile reaction products.

In high oxygen partial pressure environments, passive oxidation occurs. Passivation leads to the growth of a protective silica layer on the material surface and thus to a parabolic mass gain [11]. As the silica scale grows, the oxygen diffusion through the oxidation layer and the oxidation rate decrease [12]:

$2 \mathrm{SiC}(\mathrm{s})+3 \mathrm{O}_{2}(\mathrm{~g}) \rightarrow 2 \mathrm{SiO}_{2}(\mathrm{~s})+2 \mathrm{CO}(\mathrm{g})$

$\mathrm{Si}(\mathrm{l}, \mathrm{s})+\mathrm{O}_{2}(\mathrm{~g}) \rightarrow \mathrm{SiO}_{2}(\mathrm{~s})$

Water vapor, which is a byproduct of combustion, becomes the dominant reactant species for both silicon and SiC [13-18]. Simultaneous reaction of $\mathrm{H}_{2} \mathrm{O}$ with silica scale (Eq. (7)) results in 
parabolic formation and linear consumption of $\mathrm{SiO}_{2}$, known as para-linear oxidation kinetics [19]:

$\mathrm{Si}+2 \mathrm{H}_{2} \mathrm{O} \rightarrow \mathrm{SiO}_{2}(\mathrm{~g})+2 \mathrm{H}_{2}(\mathrm{~g})$

$\mathrm{SiC}+3 \mathrm{H}_{2} \mathrm{O} \rightarrow \mathrm{SiO}_{2}+\mathrm{CO}(\mathrm{g})+3 \mathrm{H}_{2}(\mathrm{~g})$

$\mathrm{SiO}_{2}+2 \mathrm{H}_{2} \mathrm{O}(\mathrm{g}) \rightarrow \mathrm{Si}(\mathrm{OH})_{4}(\mathrm{~g})$

In addition to the aforementioned reactions, oxidation can be affected by other factors such as scale/substrate interactions $[20,21]$, presence of impurities [12,22,23], and silica crystallization or fracture $[13,21,24]$.

Another phenomenon, highlighted by Aronovici et al. [25], is the exudation of alloyed silicon beads at temperatures above $1400{ }^{\circ} \mathrm{C}$. Oxide scale foaming during long lasting operational conditions slows down the gasses flow in the pores with a subsequent local overheating and degradation of the material [6]. It is thus very important to understand what triggers this phenomenon as it impacts the life span of porous ceramic burners' components.

There are several works in the literature concerning oxidation of $\mathrm{SiC}$ (sintered and CVD) and silicon; few of them consider the case of SiSiC by reactive silicon infiltration [6,12,25-27]. There is a lack in studies on the effect of oxidation on macro porous materials in a flowing gas caused by combustion. Moreover porous materials under oxidation present a surface to volume ratio of about one order of magnitude higher than the bulk materials studied in the literature $\left(500 \mathrm{~m}^{2} / \mathrm{m}^{3}\right.$ Vs $\left.5 \mathrm{~m}^{2} / \mathrm{m}^{3}\right)$. This has a dramatic effect on the porous material life span: we show in this work that lattice architecture changes hot gasses flow paths inside the structure and, as a consequence, affects oxidation. This work investigates the effect of cellular architecture and skeleton material microstructure on $\mathrm{SiSiC}$ porous ceramics degradation in a porous burner. The thermal tests in this study were all performed at $1400{ }^{\circ} \mathrm{C}$ (slightly below silicon's melting point) as it is the typical operating temperature in industrial burners.

\section{Experimental procedure}

\subsection{Material and sample preparation}

Regular lattices, consisting of arrays of $5 \times 5 \times 5$ cells, were designed by CAD (UGS NX 9.0, Siemens, Munich, D) with five different cell types (see Fig. 1): tetrakaidecahedron, straight cube, rotated cube (with one of the cube's main diagonal along the flow direction) and a modified octet-truss unit cell as in [28]. The cell length was kept $7 \mathrm{~mm}$. Random structures were generated from Laguerre Tessellation [29] with similar average geometrical parameters. All templates were 3D printed with the same strut diameter Ds $=0.4 \mathrm{~mm}$ using 3DLPrinter-HD 2.0 (Robot Factory S.r.l.,
It), with a resolution of 10 and $50 \mu \mathrm{m}$ in vertical and horizontal axes, respectively. Replica technique was used to convert the polymeric structures into ceramic [30]: the templates were impregnated in a slurry containing bimodal $\alpha$-SiC particles dispersed in an organic solvent by ball milling for $12 \mathrm{~h}$ and then, after adding a polymer binder, for further $36 \mathrm{~h}$ [4]. The fine and coarse SiC powders present an average particle size of $1.4 \mu \mathrm{m}$ D50 and $5 \mu \mathrm{m}$ D50, measured by laser diffraction, respectively. After drying the solvents, the resulting coating was comprised of $40 \mathrm{vol} \%$ plastic binder and $60 \mathrm{vol} \%$ of ceramic powders. Pyrolysis of the green bodies was carried out in argon $(300 \mathrm{sccm})$ with a heating rate of $40{ }^{\circ} \mathrm{C} / \mathrm{h}$ up to $500^{\circ} \mathrm{C}$, and $60^{\circ} \mathrm{C} / \mathrm{h}$ to $1000^{\circ} \mathrm{C}$, followed by dwelling for $1 \mathrm{~h}$ and natural cooling. Decomposition of the green body leads to a skeleton material with $\sim 30 \%$ porosity. This porosity allows liquid silicon to fill the microstructure via capillary forces. Reactive infiltration using silicon of $99.5 \%$ purity was performed by heating samples at $1500{ }^{\circ} \mathrm{C}$ for $4 \mathrm{~h}$ in a $10^{-2}$ mbar residual pressure to form $\beta$-SiC according to the following reaction [31]:

$\mathrm{Si}(\mathrm{l})+\mathrm{C}(\mathrm{s}) \rightarrow \mathrm{SiC}(\mathrm{s})\left[\Delta \mathrm{H}=-73 \mathrm{~kJ} \mathrm{~mol}^{-1}\right]$

The resulting microstructures consisted of $\alpha$-SiC particles, reaction bonded SiC and unreacted silicon ( $\sim 20 \%)$. Two opposite surfaces of each lattice were milled using diamond tools to realize parallel surfaces (Fig. 1) for compression tests.

\subsection{Oxidation tests and characterization}

45 samples were produced and divided in three groups as shown in Table 1. Samples of group I were oxidized in a furnace (LHT 08/16 Nabertherm GmbH, Bremen, D) in calm air atmospheric conditions. The furnace was heated up $\left(10^{\circ} \mathrm{C} / \mathrm{min}\right)$ to $1400{ }^{\circ} \mathrm{C}$, kept for one hour at that temperature and then naturally cooled to prevent thermal shock and preserve integrity of the oxide layer.

Group II specimens were tested using a porous burner. Porous burner is an advanced combustion technology that offers flameless and stable reaction of fuel and air with a homogeneous temperature field on the surface [2]. The schematic set up of the burner with specimens is shown in Fig. 2. Methane and air enter into the system, pass the porous alumina insulation and react within the pores of the $\mathrm{SiSiC}$ foam (similar to the ones produced in this work). In each run three specimens of the same morphology were placed in the center of the burner. The rest of the burner's surface was covered with refractory alumina (Fig. 2). The power and the ratio of actual to stoichiometric amount of air $(\lambda)$ feeding the system were adjusted to $25 \mathrm{~kW}$ and $\lambda=1.3$, respectively. Tests were carried out following the subsequent procedure: flame ignition, dwelling, and shut down by closing the fuel valve while keeping the air flowing. The tests were consecutively repeated four times. Heating consisted in ramping up to $1400{ }^{\circ} \mathrm{C}$ (in the hottest spot on the lattice) at about $36^{\circ} \mathrm{C} / \mathrm{s}$. Samples were kept at $1400^{\circ} \mathrm{C}$ for

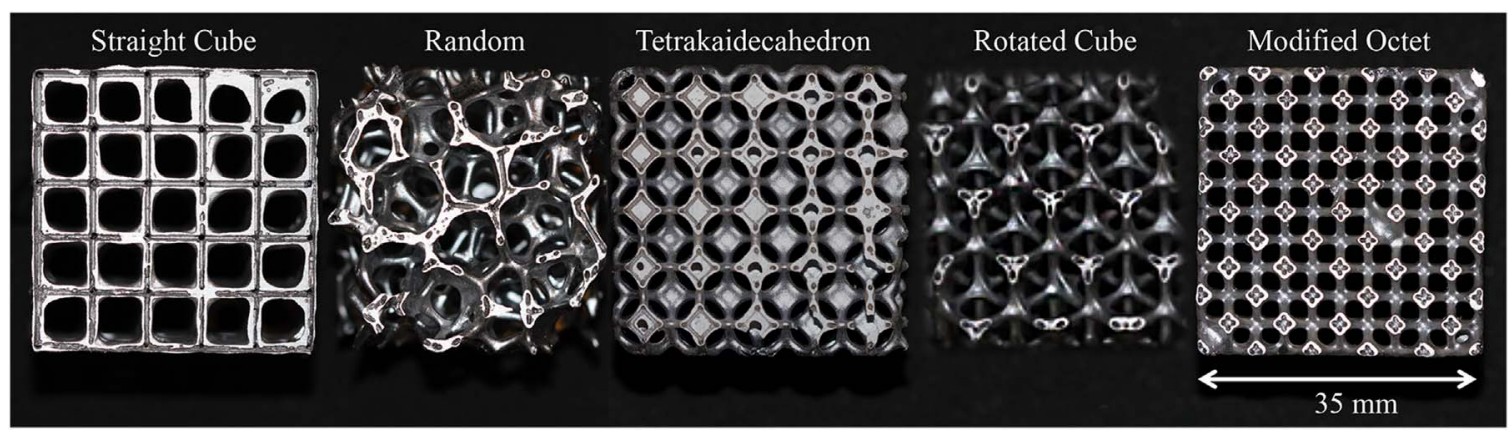

Fig. 1. Front view of the five $\mathrm{SiSiC}$ lattices produced by replica technique in this work. 
Table 1

Produced specimens and their distribution into three test groups.

\begin{tabular}{lllllll}
\hline & $\begin{array}{l}\text { Foam } \\
\text { cube }\end{array}$ & $\begin{array}{l}\text { Rotated } \\
\text { cube }\end{array}$ & Tetrakaidecahedron & $\begin{array}{c}\text { Octet } \\
\text { group }\end{array}$ \\
\hline Group I & 3 & 3 & 3 & 3 & 3 & 15 \\
Group II & 3 & 3 & 3 & 3 & 3 & 15 \\
Group III & 3 & 3 & 3 & 3 & 3 & 15 \\
$\begin{array}{l}\text { Total/lattice } \\
\text { type }\end{array}$ & 9 & 9 & 9 & 9 & 9 & 45 \\
\hline
\end{tabular}

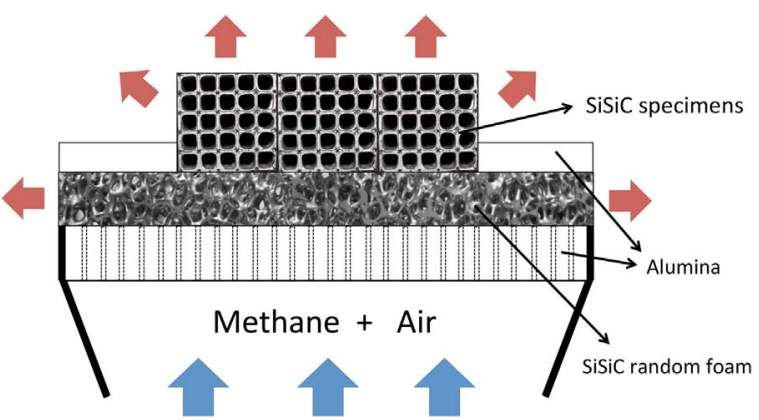

Fig. 2. Schematic representation of the test set up with the porous burner and three cubic samples placed on it.

Table 2

Thermal tests of each of the three groups of specimens.

\begin{tabular}{llll}
\hline & $\begin{array}{l}\text { Thermal } \\
\text { treatments }\end{array}$ & Temperature $\left({ }^{\circ} \mathrm{C}\right)$ & Cycles \\
\hline Group I & In furnace & 1400 & $\begin{array}{l}\text { One cycle with slow cool- } \\
\text { ing and heating. }\end{array}$ \\
Group II & In porous burner & $\begin{array}{l}\text { Max. } 1400(1100- \\
1400)\end{array}$ & $\begin{array}{l}\text { Four cycles with } 36{ }^{\circ} \mathrm{C} / \mathrm{s} \\
\text { heating and } 29^{\circ} \mathrm{C} / \mathrm{s} \\
\text { cooling. }\end{array}$ \\
Group III & As produced & &
\end{tabular}

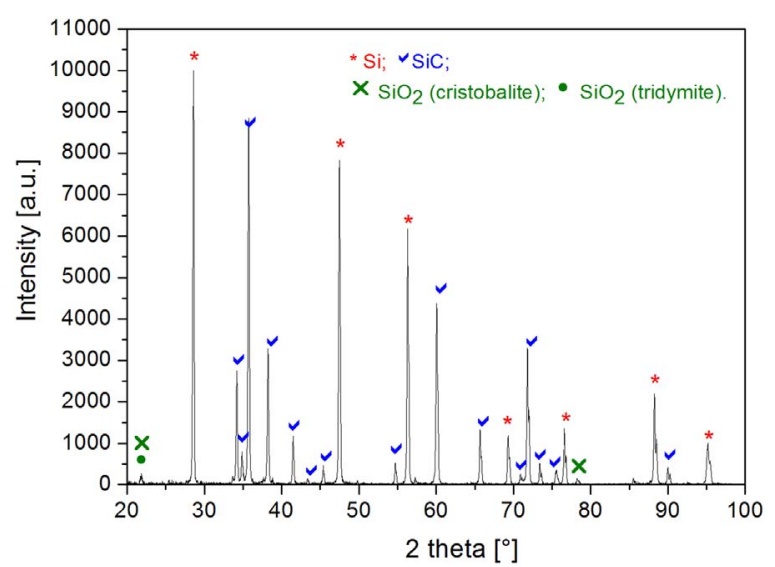

Fig. 3. XRD analysis of a pulverized strut from cubic lattice after thermal tests of group I, showing the formation of cristobalite and tridymite.

$15 \mathrm{~min}$ and then cooled to $400{ }^{\circ} \mathrm{C}$ at about $29^{\circ} \mathrm{C} / \mathrm{s}$. The temperature of the samples was measured using a two-color pyrometer (PYROSPOT DG 4N, DIAS Infrared GmbH, D). Group III samples were kept as produced. (Table 2) To evaluate the strength retention of the specimens, all samples of three groups were mechanically tested under compression.

Different characterization techniques were used to study the oxidation behavior. Optical microscopy (Leica DMLM, D) and a scanning electron microscopy (SEM) equipped with energy dispersive X-ray spectroscopy (JSM6010plus/LA, JEOL, Tokyo, JP) were

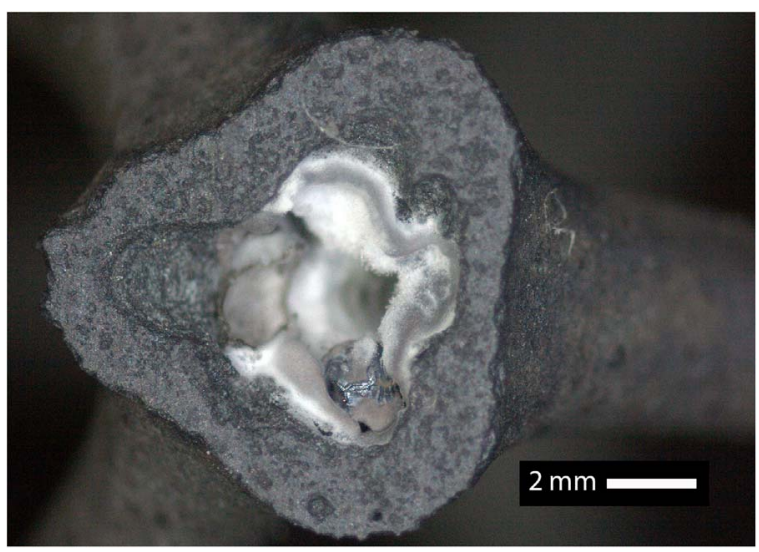

Fig. 4. Rotated cubic sample of group I after thermal oxidation. The cavities inside the struts oxidized in a lower oxygen partial pressure. That can result in formation of silica whiskers (white features). An exuded silicon alloy bead is also evident inside the strut.

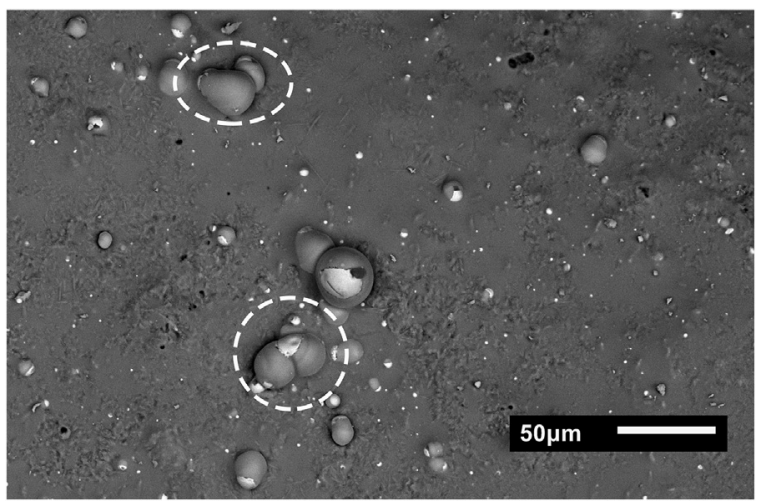

Fig. 5. Silicon alloy bead on the surface of a cubic lattice belonging to group I. White features correspond to heavier elements ( $\mathrm{Fe}, \mathrm{Cr}$ ). In the dashed areas, beads coalescing in larger ones.

used to evaluate the surface morphology and struts microstructure before and after the tests. Single struts of Group I and II were pulverized for X-ray diffraction (XRD) using $\mathrm{Cu} \mathrm{K} \alpha$ radiation analysis (PW 3830, Philips, Eindhoven, the Netherlands). One strut was extracted from each porous architecture and pulverized for the XRD tests. As a result the signal from the oxide phases is quite low, nevertheless we detected the same phases shown in the literature $[6,7,17]$. Due to silicon alloy formation and loss, peripheral strut rupture during the thermal treatment in the porous burner of the most delicate structures, the recorded mass change data were not reliable and thus not reported in detail. Compression tests were conducted in a typical compression test set-up using a universal testing machine (Z050, Zwick/Roell Ulm, D) with cross head speed of $0.1 \mathrm{~mm} / \mathrm{min}$. The displacement of the cross head and the loads were measured using the integrated position control system of the machine and a $50 \mathrm{kN}$ load cell (Zwick/Roell, D) respectively.

\section{Results and discussion}

\subsection{Oxidation behavior}

Specimens of group I, which were oxidized isothermally in calm air, did not show any visible mechanical damage or crack. A general mass gain was observed in all specimens in agreement with our previous work [25], suggesting passivation as the dominant oxidation mode. Passivation produces a dense oxide layer of $\mathrm{SiO}_{2}$ according to reactions (3) and (4). The formation of this 


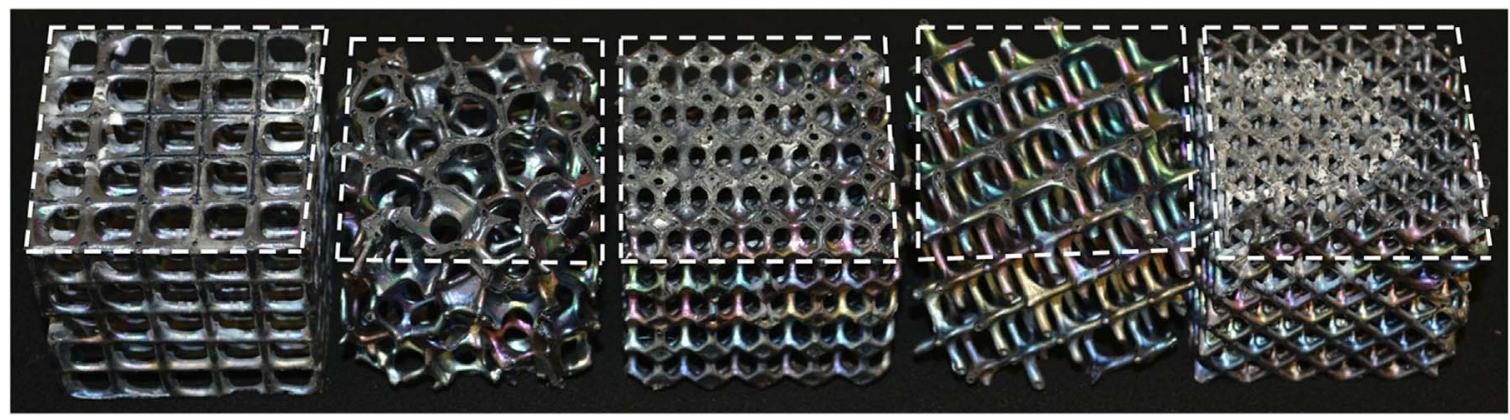

Fig. 6. Five different lattices of group II after thermal tests in porous burner. The dashed lines mark out the surface at the maximum temperature $1400{ }^{\circ} \mathrm{C}$.

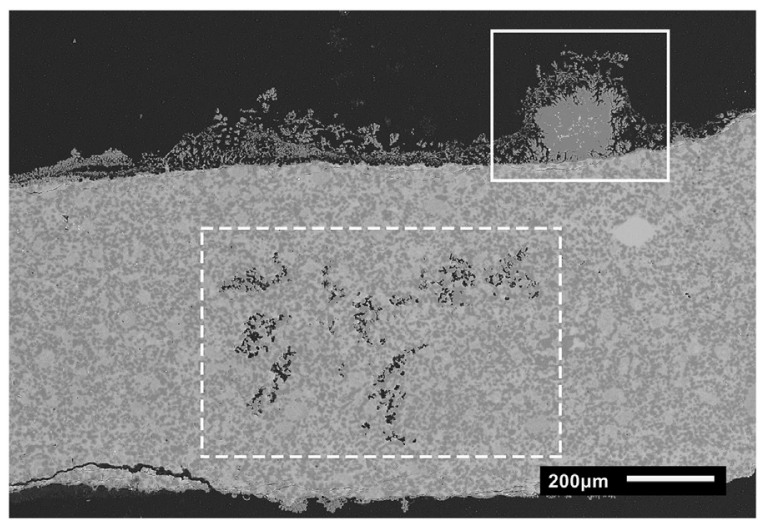

Fig. 7. A strut of octet samples of group II after tests. The topside of the strut is the windward side, which had a ticker silica scale. Silicon depleted regions are shown in the dashed rectangle.

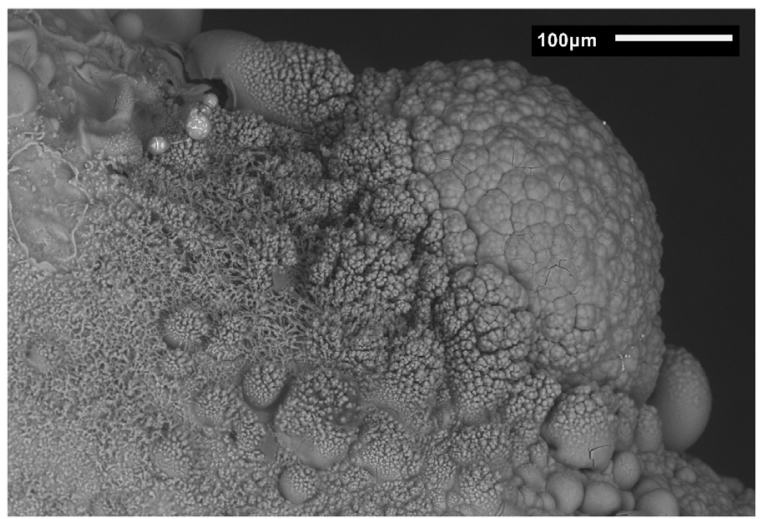

Fig. 8. SEM image of the surface (the hot zone) of octet specimen of group II after the tests. The swelled region correspond to an exuded bead after severe oxidation (a cross section of it can be seen also in the rectangle in Fig. 7).

protective oxide scale decreases the oxygen diffusion rate and thus decelerates the oxidation process [12]. XRD pattern for the skeleton material after the tests revealed that this oxidation layer is likely made of cristobalite and tridymite (Fig. 3).

All the samples used in this study present a cylindrical cavity inside the struts due to the replica manufacturing technique [32]. The presence of this cavity may lead to oxidation of inner surface of the struts. Due to limited oxygen supply, the surface of these cavities may undergo either active oxidation (resulting in loss of material) or formation of silica whiskers [26]. Fig. 4 shows the formation of silica whiskers inside the strut [25].

In addition to oxidation, scattered silicon alloy beads of different size were observed, mainly on the outer surface of the samples (Fig. 5). EDS analyses of the beads showed the presence of iron, titanium and chromium. These impurities come from the silicon

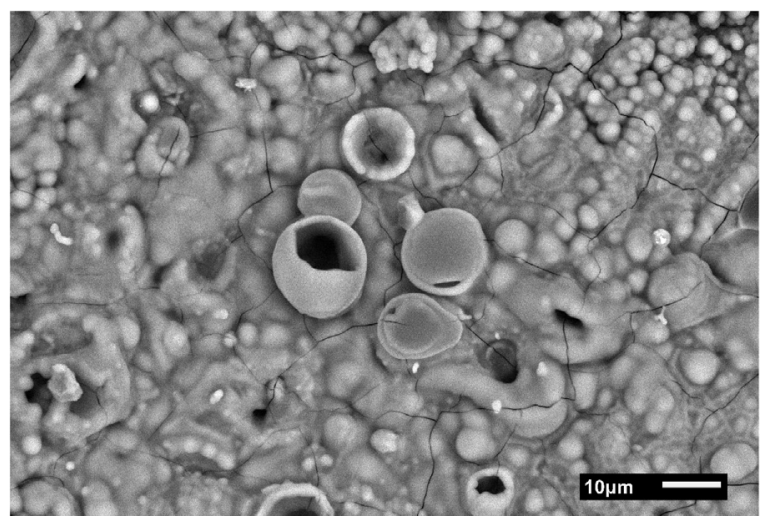

Fig. 9. Bubble and craters formed in process of silica formation. Craters are filled with silica after the gas explosion. The silica surface is full of cracks made in thermal cycles due to large difference of its thermal expansion with substrate.

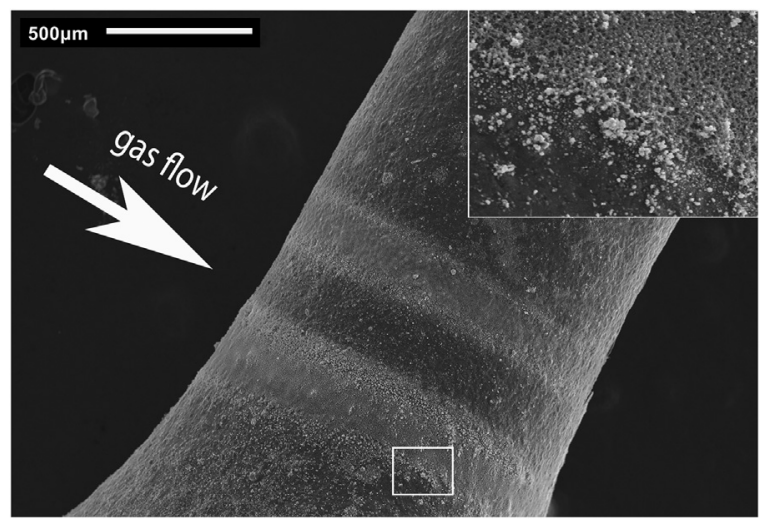

Fig. 10. Formation of two stripes of silica on a strut of a cubic sample of group II. The white arrow shows the gas flow direction.

(purity: 99.5\%). During high temperature conditioning being them alloyed with silicon melted at low temperatures (lower than the test temperature). As pure silicon shrinks upon melting, it further favors the oxidation process by opening up new pores in the microstructure. On the other hand, silica while forming expands and squeezes out the molten silicon alloy from the microstructure [25]. The low wettability of the silicon alloy on $\mathrm{SiO}_{2}$ [33] favors beads formation on the strut's outer surface. These beads then coalesce in larger and larger beads (Fig. 5 dashed lines).

Unlike group I, samples of group II showed local corrosion due to inhomogeneous temperature and gas velocity in the lattices on the burner. The average gas velocity, entering the samples, was estimated around $5 \mathrm{~m} / \mathrm{s}$. The bottom side was at $1400{ }^{\circ} \mathrm{C}$ whereas the top part was at $1100{ }^{\circ} \mathrm{C}$. This temperature gradient resulted in different struts' coloration, which can be due to formation of different thicknesses of the silica scale [34]. Silicon alloy beads were 


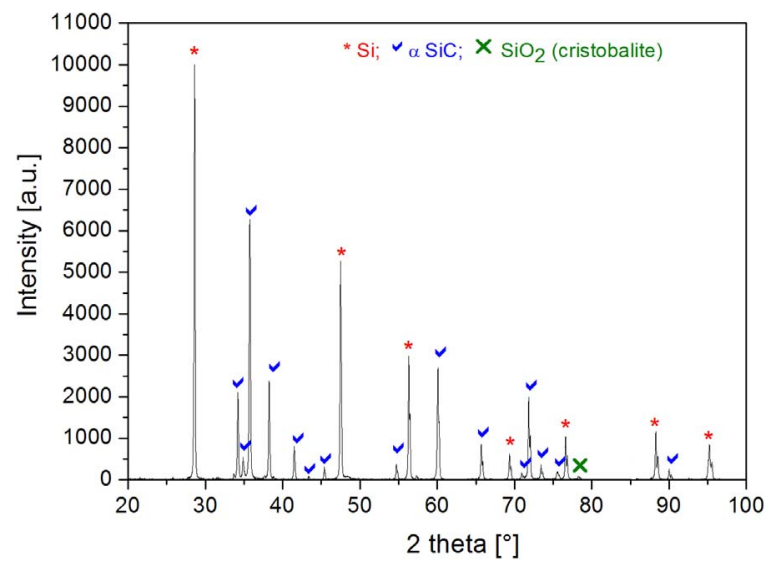

Fig. 11. XRD analysis of a pulverized strut in cubic lattice (group II).

observed only on the bottom part of the lattices (dashed rectangles in Fig. 6).

The ratio of actual to stoichiometric amount of air $(\lambda)$ in burner was 1.3 resulting in lean reaction of methane in air. The outlet gas flow was calculated to contain about $15 \mathrm{vol} \% \mathrm{H}_{2} \mathrm{O}$ and $7 \mathrm{vol} \% \mathrm{CO}_{2}$, according to Eq. (9) and $5 \mathrm{vol} \% \mathrm{O}_{2}$ due to the present excess air.

$\mathrm{CH}_{4}(\mathrm{~g})+2 \mathrm{O}(\mathrm{g}) \rightarrow \mathrm{CO}_{2}(\mathrm{~g})+2 \mathrm{H}_{2} \mathrm{O}(\mathrm{g})$

Gases which such compositions can degrade both silicon and $\mathrm{SiC}$ phases [12]. Because of the high percentage of water vapor, the samples faced a more severe oxidation in the hot zones compared to the samples of group I tested isothermally [35]. Presence of water vapor increases the oxidation rate of both $\mathrm{Si}$ and $\mathrm{SiC}$ by an order of magnitude $[17,18,36] . \mathrm{H}_{2} \mathrm{O}$ can also increase the porosity of the oxide layer [35]. Due to high gas velocity (over $1 \mathrm{~m} / \mathrm{s}$ ) inside the lattices, the oxidation kinetics can change to para-linear behavior following the simultaneous formation and volatilization of $\mathrm{SiO}_{2}$ (Eqs. (5)-(7)) [37].

At the bottom of some lattices, where the temperature was $\sim 1400{ }^{\circ} \mathrm{C}$, and especially in the octet, tetrakaidecahedron and cubic structures, a distinct thick layer $(20-200 \mu \mathrm{m})$ of porous silica was formed (Fig. 7). This porous layer fully covered the windward side of the struts, while the leeward side was less affected. The severe oxidation was likely because of the high percentage of water vapor. Moreover molten silicon exuded on the surface in group II facilitating the oxidation. The exuded beads depleted the inner microstructure of free silicon leading to the formation of porosity (dashed rectangle in Fig. 7) [38]. Fig. 8 depicts bubbles and craters together with whiskers in these regions. Gaseous products of the oxidation reactions may initially diffuse to the surface. With the oxide layer thickening, bubbles form into the viscous medium (most likely an amorphous silica film [12]) and move toward the external surface. On the surface, they explode resulting in craters and filled-out bubbles [16] (Fig. 9). These craters, exposing the bare SiSiC surface to the open environment, are then healed by the viscous flow of silica [20].

In the colder part of the samples, the oxidation was negligible. However, on many struts, arc-shaped stripes of white silica were observed. This phenomenon took its form along the flow direction around the struts. These observations reveal the onset of oxidation on a single strut. Fig. 10 depicts SEM images from the surface of the oxide layers, characterized by silica wires. This is similar to what is reported as transition from active to passive oxidation mode in presence of oxygen [29]. This silica layer was loosely attached to the substrate resulting spallation in some zones, likely during heating and cooling ramps. XRD analysis of the strut showed the presence of cristobalite (Fig. 11). We propose the mechanism of the ring shaped oxide layer formation as follows:

$\mathrm{SiO}_{2}$ islands form on the surface, most likely in a point with higher concentration of impurities such as iron. At the same time $\mathrm{SiO}$ is produced and diffuses away from the surface [26]. The $\mathrm{SiO}_{2}$ islands act as nucleation points for $\mathrm{SiO}$ reacting with $\mathrm{O}_{2}$ and the formation of $\mathrm{SiO}_{2}$ rods [8]. In stationary air, this phenomenon results in circular regions on the surface [10]. In a gas flow over the struts, the very first nucleation zones are formed in the stagnation point (Fig. 12A). SiO is then transported by the gas and further oxidizes along the flow path on a single strut (Fig. 12B). In a turbulent flow regime, such as in a porous burner, the oxide layer formation continues up to the point where the flow separates from the strut's surface (Fig. 12C).

This porous silica layer was observed mainly on the straight cubic samples than on the other lattices. Silica was mainly cristobalite (Fig. 11). Based on the proposed mechanism, lattices with struts misaligned in respect of the gasses flow (i.e. some struts of the octet, tetrakaidecahedron and straight cubic structures) get a higher chance to show this oxidation pattern, while it will be much less evident in rotated cubes and random foams (comprised of more struts aligned with the gasses flow).

\subsection{Mechanical strength}

In order to evaluate the effect of different lattice structures on
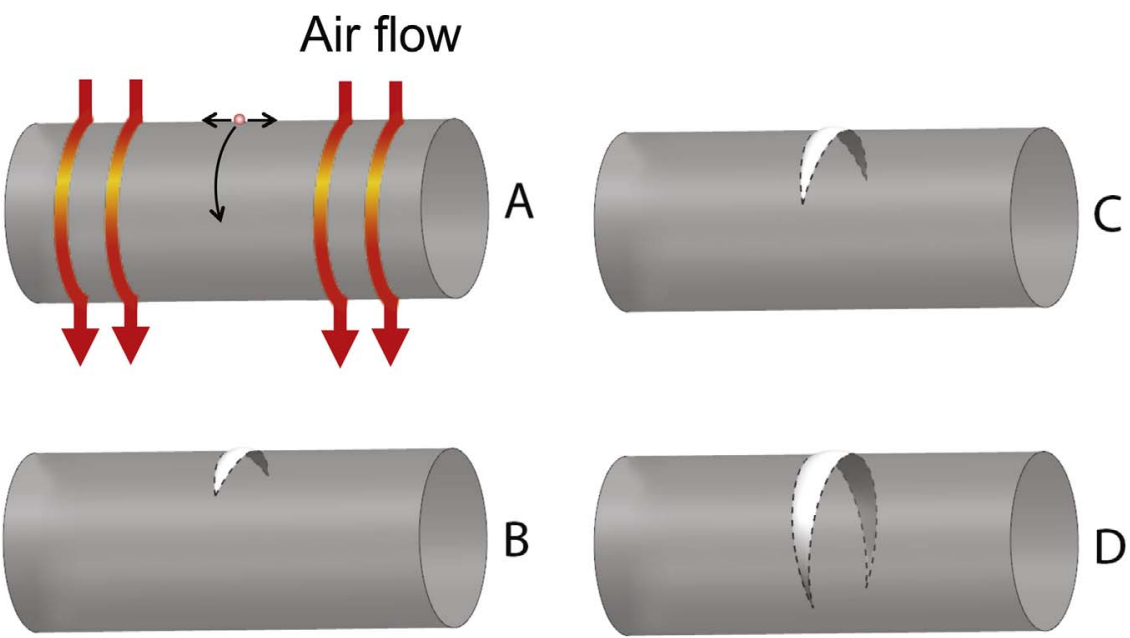

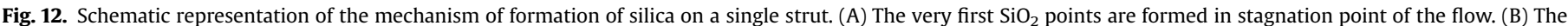
layer grows in both directions on the strut along the flow stream. (C) and (D) The gradual growth is much faster along the gas flow. 


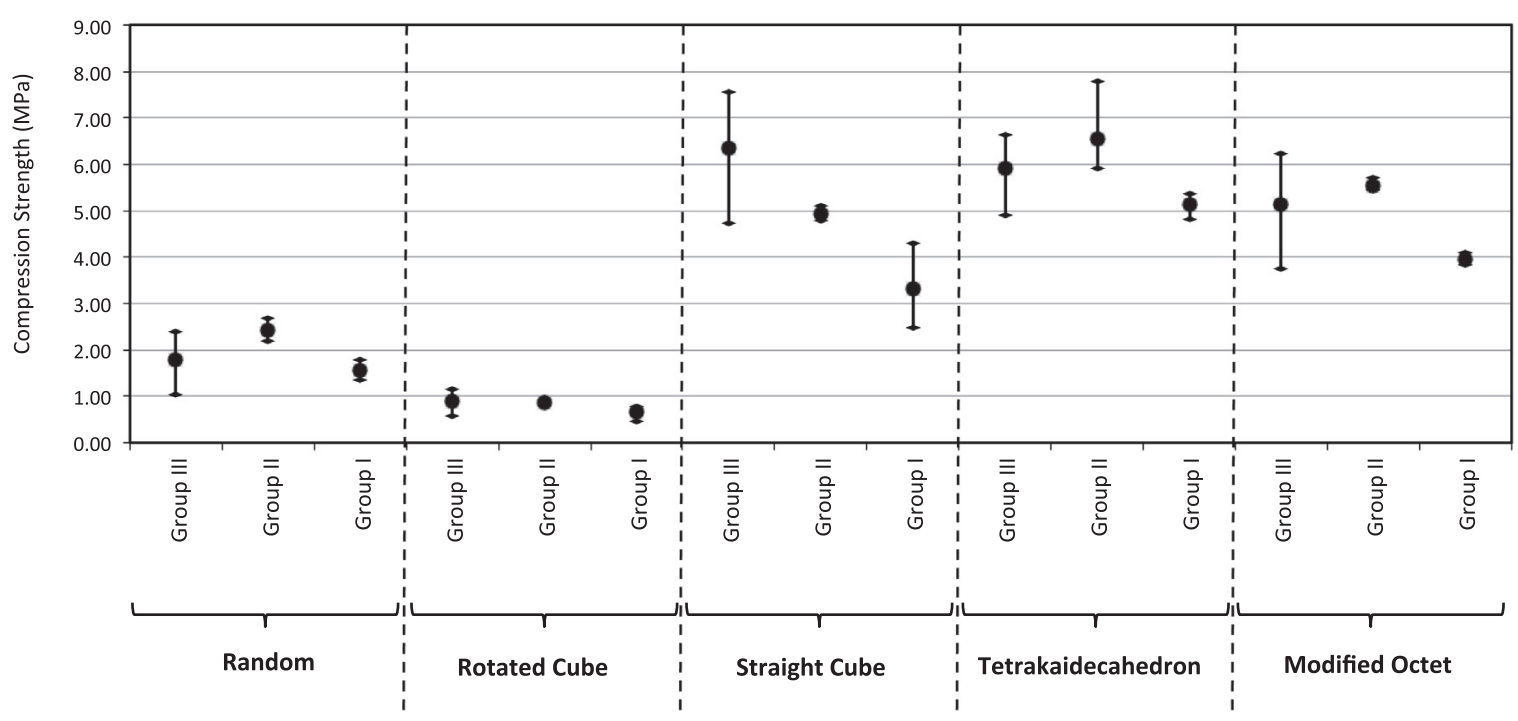

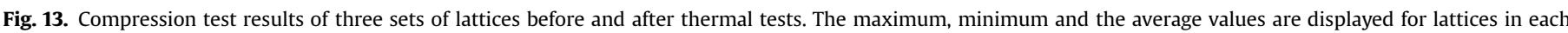
group. While strength values of group II specimens did not differ from the as-produced ones, samples of group I showed a decreased retained strength.

the retained strength after the thermal cycling, isothermally oxidized (group I), thermally cycled (group II) and the as-produced (group III) samples were mechanically tested under compression. Load-displacement data of the samples showed two main regimes. An initial linear regime due to the elastic deformation of the struts. Further on, a new regime appeared due to the gradual failure of some struts, followed by the collapse of the entire porous architecture. This is in agreement with the literature [39] reporting damage accumulation mechanism in compression tests of ceramic foams. Fig. 13 shows the result of the tests on samples of the three groups. Samples of group I showed a decrease in strength compared to as produced specimens. This can be explained by silicon melting and leaving the specimens and the consequent formation of porosity (Fig. 7), which reduces the strength of the skeleton's material. Results of group II specimens did not differ from the asproduced ones. One reason is that the phenomena described above occurred in a limited region of the sample facing the hottest zones. The rest of the structure was neither affected by silicon depletion nor heavily oxidized. In some sample the strength even increased; this can be due to the blunting of surface cracks by the formation of silica scale $[23,40]$.

It was also noticed that, while intact samples strength values were broadly distributed, the thermally treated specimens of group I and II had very low variations, which may suggest an increased uniformity in flaw distribution. This phenomenon is also reported for sintered $\mathrm{SiC}[41]$.

\section{Conclusions}

Oxidation behavior of five different SiSiC lattice structures were studied at $1400{ }^{\circ} \mathrm{C}$. A group of specimens were thermally tested in calm air. The second group faced thermo-cyclic oxidation in a porous burner. It was shown that at $1400{ }^{\circ} \mathrm{C}$, there are two main limiting factors in using SiSiC materials: silicon alloy bead formation and combustion products such as $\mathrm{H}_{2} \mathrm{O}$ and $\mathrm{CO}_{2}$. Silicon alloy melted out of the samples, introducing more porosity in the microstructure. This resulted in decreased retention strength and rapid oxidation on the surface and inside porosities. High partial pressure of $\mathrm{H}_{2} \mathrm{O}$ in the combustion environment of the porous burner resulted in a porous silica glass layer on the hot zones of samples group II. This severe oxidation was also due to liquid silicon that melted out from the microstructure. In addition to this, silica was formed along the fluid flow on single struts. This can be explained as initial silica formation in the stagnation point of the flow and its gradual growth along the gas flow. The severity of oxidation in samples group II was different depending on lattice morphology. It was observed that straight cubic lattices, having more struts perpendicular to the gas flow direction, offer more stagnation zones and higher oxidation. Therefore, in designing lattices for high temperature applications, in addition to parameters such as thermo-mechanical properties or permeability, one should also consider the effect of lattice type on corrosion.

\section{Acknowledgments}

The research leading to these results has received funding from the European Union Seventh Framework Program (FP7/20072013) under Grant agreement No. 325383, Project "Biogas robust processing with combined catalytic reformer and trap" (BIOROBUR). This research was also based upon work performed in cooperation with CTI Swiss Competence Center for Energy Research (SCCER Heat and Electricity Storage).

Authors thank Politecnico di Torino for the XRD analysis of the samples.

\section{References}

[1] S. Gianella, D. Gaia, A. Ortona, High temperature applications of SiSiC cellular ceramics, Adv. Eng. Mater. 14 (12) (2012) 1074-1081.

[2] D. Trimis, F. Durst, Combustion in a porous medium-advances and applications, Combust. Sci. Technol. 121 (1-6) (1996) 153-168.

[3] T. Fend, B. Hoffschmidt, R. Pitz-Paal, O. Reutter, P. Rietbrock, Porous materials as open volumetric solar receivers: experimental determination of thermophysical and heat transfer properties, Energy 29 (5-6) (2004) 823-833.

[4] A. Ortona, C. D'Angelo, S. Gianella, D. Gaia, Cellular ceramics produced by rapid prototyping and replication, Mater. Lett. 80 (2012) 95-98.

[5] A. Ortona, D. Trimis, V. Uhlig, R. Eder, S. Gianella, P. Fino, G. D'Amico, E. Boulet, C. Chazelas, T. Grämer, E. Cresci, J.G. Wünning, H. Altena, F. Beneke, M. Debier $\mathrm{SiSiC}$ heat exchangers for recuperative gas burners with highly structured surface elements, Int. J. Appl. Ceram. Technol. 11 (5) (2014) 927-937.

[6] F.R.A. Mach, F.V. Lssendorff, A. Delgado, Experimental investigation of the oxidation behavior of SiSiC foams, Ceram. Eng. Sci. Proc. 29 (2008) 299.

[7] S.P.A. Ortona, Aging of reticulated Si-SiC foams in porous burners, Adv. Appl. Ceram. 109 (4) (2010) 246-251.

[8] J.W. Hinze, H.C. Graham, The active oxidation of $\mathrm{Si}$ and $\mathrm{SiC}$ in the viscous gasflow regime, J. Electrochem. Soc. 123 (7) (1976) 1066-1073.

[9] E.A. Gulbransen, K.F. Andrew, F.A. Brassart, The oxidation of silicon carbide at $1150^{\circ}$ to $1400{ }^{\circ} \mathrm{C}$ and at $9 \times 10^{-3}$ to $5 \times 10^{-1}$ Torr oxygen pressure, $\mathrm{J}$. 
Electrochem. Soc. 113 (12) (1966) 1311-1314.

[10] N.S. Jacobson, D.L. Myers, Active oxidation of SiC, Oxid. Met. 75 (1-2) (2010) $1-25$.

[11] C. Wagner, Passivity during the oxidation of silicon at elevated temperatures, J Appl. Phys. 29 (9) (1958) 1295-1297.

[12] N.S. Jacobson, Corrosion of silicon-based ceramics in combustion environments, J. Am. Ceram. Soc. 76 (1) (1993) 3-28.

[13] P.J. Jorgensen, M.E. Wadsworth, I.B. Cutler, Effects of water vapor on oxidation of silicon carbide, J. Am. Ceram. Soc. 44 (6) (1961) 258-261.

[14] H. Cappelen, K.H. Johansen, K. Motzfeldt, J. Weidlein, O. Wahlberg, Oxidation of silicon carbide in oxygen and in water vapour at $1500{ }^{\circ} \mathrm{C}$., Acta Chem. Scand 35a (1981) 247-254.

[15] T. Narushima, T. Goto, Y. Iguchi, T. Hirai, High-temperature oxidation of chemically vapor-deposited silicon carbide in wet oxygen at 1823 to 1923 K, J. Am. Ceram. Soc. 73 (12) (1990) 3580-3584.

[16] M. Maeda, K. Nakamura, T. Ohkubo, Oxidation of silicon carbide in a wet atmosphere, J. Mater. Sci. 23 (11) (1988) 3933-3938.

[17] E.J. Opila, Variation of the oxidation rate of silicon carbide with water-vapor pressure, J. Am. Ceram. Soc. 82 (3) (1999) 625-636.

[18] B.E. Deal, A.S. Grove, General relationship for the thermal oxidation of silicon, J. Appl. Phys. 36 (12) (1965) 3770-3778.

[19] E.J. Opila, Oxidation and volatilization of silica formers in water vapor, J. Am. Ceram. Soc. 86 (8) (2003) 1238-1248.

[20] R. Raj, K. Terauds, Bubble nucleation during oxidation of SiC, J. Am. Ceram. Soc 98 (8) (2015) 2579-2586.

[21] B. Harder, N. Jacobson, D. Myers, Oxidation transitions for SiC Part II. Passiveto-active transitions, J. Am. Ceram. Soc. 96 (2) (2013) 606-612.

[22] E.J. Opila, Oxidation kinetics of chemically vapor-deposited silicon carbide in wet oxygen, J. Am. Ceram. Soc. 77 (3) (1994) 730-736.

[23] S.C. Singhal, F.F. Lange, Effect of alumina content on the oxidation of hotpressed silicon carbide, J. Am. Ceram. Soc. 58 (9-10) (1975) 433-435.

[24] L.U.J.T. Ogbuji, M. Singh, High-temperature oxidation behavior of reactionformed silicon carbide ceramics, J. Mater. Res. 10 (12) (1995) 3232-3240.

[25] M. Aronovici, G. Bianchi, L. Ferrari, M. Barbato, S. Gianella, G. Scocchi, A. Ortona, Heat and mass transfer in ceramic lattices during high-temperature oxidation, J. Am. Ceram. Soc. 98 (8) (2015) 2625-2633.

[26] H. Nanri, M. Shirai, N. Takeuchi, S. Ishida, K. Watanabe, M. Wakamatsu,
Oxidation behavior of Si-SiC at high temperature, J. Ceram. Soc. Jpn. 105 (1217) (1997) 15-20.

[27] R. Röttenbacher, G. Willmann, SiSiC - a material for high temperature ceramic heat exchangers, in: H. Kröckel, M. Merz, O.V.D. Biest (Eds.), Ceramics in Advanced Energy Technologies, Springer, Netherlands, 1984, pp. 231-249.

[28] A. Ortona, E. Rezaei, Modeling the properties of cellular ceramics: from foams to lattices and back to foams, Adv. Sci. Technol. 91 (2014) 70-78.

[29] C. Lautensack, Fitting three-dimensional Laguerre tessellations to foam structures, J. Appl. Stat. 35 (9) (2008) 985-995.

[30] J. Adler, M. Teichgraeber, G. Standke, H. Jaunich, H. Stoever, R. Stoetzel, Open Cell Expanded Ceramic With a High Level of Strength, and Process for the Production thereof, European Patent 0 907, 1999, 621.

[31] E. Rezaei, G. Bianchi, S. Gianella, A. Ortona, On the nonlinear mechanical behavior of macroporous cellular ceramics under bending, J. Eur. Ceram. Soc. 34 (10) (2014) 2133-2141.

[32] S. Karl, A.V. Somers, Method of Making Porous Ceramic Articles, US3090094 A, May 21, 1963.

[33] R. Sangiorgi, M.L. Muolo, D. Chatain, N. Eustathopoulos, Wettability and work of adhesion of nonreactive liquid metals on silica, J. Am. Ceram. Soc. 71 (9) (1988) 742-748.

[34] H.C. Evitts, H.W. Cooper, S.S. Flaschen, Rates of formation of thermal oxides of silicon, J. Electrochem. Soc. 111 (6) (1964) 688-690.

[35] P.F. Tortorelli, K.L. More, Effects of high water-vapor pressure on oxidation of silicon carbide at $1200{ }^{\circ} \mathrm{C}$, J. Am. Ceram. Soc. 86 (8) (2003) 1249-1255.

[36] E.J. Opila, R.E. Hann, Paralinear oxidation of CVD SiC in water vapor, J. Am. Ceram. Soc. 80 (1) (1997) 197-205.

[37] E.J. Opila, Water vapor effects on high-temperature oxidation and volatilization of ceramics, J. Am. Ceram. Soc. 86 (8) (2003), 1237-1237.

[38] J. Adler, Cellular ceramics made of silicon carbide ceramics for burner technology, presented at the The American Ceramic Society, 2009.

[39] R. Brezny, D.J. Green, Uniaxial strength behavior of brittle cellular materials, J. Am. Ceram. Soc. 76 (9) (1993) 2185-2192.

[40] F.F. Lange, Healing of surface cracks in SiC by oxidation, J. Am. Ceram. Soc. 53 (5) (1970), 290-290.

[41] T.E. Easler, R.C. Bradt, R.E. Tressler, Strength distributions of SiC ceramics after oxidation and oxidation under load, J. Am. Ceram. Soc. 64 (12) (1981) 731-734. 